\title{
Monitoring mosquitoes in urban Dar es Salaam: Evaluation of resting boxes, window exit traps, CDC light traps, Ifakara tent traps and human landing catches
}

Nicodem J Govella ${ }^{1,2^{*}}$, Prosper P Chaki ${ }^{1,2}$, John M Mpangile ${ }^{1,3}$, Gerry F Killeen ${ }^{1,2}$

\begin{abstract}
Background: Ifakara tent traps (ITT) are currently the only sufficiently sensitive, safe, affordable and practical method for routine monitoring host-seeking mosquito densities in Dar es Salaam. However, it is not clear whether ITT catches represent indoors or outdoors biting densities. ITT do not yield samples of resting, fed mosquitoes for blood meal analysis.

Methods: Outdoors mosquito sampling methods, namely human landing catch (HLC), ITT (Design B) and resting boxes (RB) were conducted in parallel with indoors sampling using HLC, Centers for Disease Control and Prevention miniature light traps (LT) and RB as well as window exit traps (WET) in urban Dar es Salaam, rotating them thirteen times through a $3 \times 3$ Latin Square experimental design replicated in four blocks of three houses. This study was conducted between $6^{\text {th }}$ May and $2^{\text {rd }}$ July 2008, during the main rainy season when mosquito biting densities reach their annual peak.

Results: The mean sensitivities of indoor RB, outdoor RB, WET, LT, ITT (Design B) and HLC placed outdoor relative to HLC placed indoor were 0.01, 0.005, 0.036, 0.052, 0.374, and 1.294 for Anopheles gambiae sensu lato (96\% An. gambiae s.s and $4 \%$ An. arabiensis), respectively, and $0.017,0.053,0.125,0.423,0.372$ and 1.140 for Culex spp, respectively. The ITT (Design B) catches correlated slightly better to indoor $\mathrm{HLC}\left(r^{2}=0.619, \mathrm{P}<0.001, r^{2}=0.231, \mathrm{P}=0.001\right)$ than outdoor HLC $\left(r^{2}=0.423, P<0.001, r^{2}=0.228, P=0.001\right)$ for An. gambiae s.l. and Culex spp respectively but the taxonomic composition of mosquitoes caught by ITT does not match those of the indoor HLC ( $\chi^{2}=607.408$, degrees of freedom $=18, P<0.001)$. The proportion of An. gambiae caught indoors was unaffected by the use of an LLIN in that house. Conclusion: The RB, WET and LT are poor methods for surveillance of malaria vector densities in urban Dar es Salaam compared to ITT and HLC but there is still uncertainty over whether the ITT best reflects indoor or outdoor biting densities. The particular LLIN evaluated here failed to significantly reduce house entry by An. gambiae s.l. suggesting a negligible repellence effect.
\end{abstract}

\section{Background}

In urban Dar es Salaam, Tanzania the principal malaria vectors are species of $A n$. gambiae complex and $A n$. funestus [1]. Culex spp, is also present in larger numbers [1], causing appreciable nuisance and is known to transmit Lymphatic Filariasis [2-6]. Human infection with

\footnotetext{
* Correspondence: govella@ihi.or.tz

'Ifakara Health Institute, Coordination Office, PO Box 78373, Kiko Avenue, Mikocheni, Dar es Salaam, United Republic of Tanzania

Full list of author information is available at the end of the article
}

Wuchereria bancrofti was generally thought to be increasing in urban African communities due to rapid urbanization coupled with inadequate sanitary facilities which provide ideal breeding habitats [7] for mosquitoes in the Culex pipiens complex (Culex pipiens L Culex quinquefasciatus,) [8], which is a major vector of lymphatic filariasis in South Asia, East Africa and Americas particularly in urban areas [3,9-14]. Although recent global effort to eliminate the filarial infections through mass drug administration (MDA) has reversed this

\section{Biomed Central}

(c) 2011 Govella et al; licensee BioMed Central Ltd. This is an Open Access article distributed under the terms of the Creative Commons Attribution License (http://creativecommons.org/licenses/by/2.0), which permits unrestricted use, distribution, and reproduction in any medium, provided the original work is properly cited. 
trend to some degree [15-17], it is becoming increasingly clear that elimination of filariasis transmission is unlikely to be achieved by MDA alone $[5,18]$ so vector control remains an option to be considered that will necessitate routine monitoring of vector densities.

In its initial stages, routine monitoring of adult mosquito densities by the Dar es Salaam Urban Malaria Control program (UMCP) was only possible with the laborious, uncomfortable, requiring intensive supervision and potentially hazardous human landing catch (HLC) for several years $[1,19]$. The Dar es Salaam Urban Malaria Control program relies on weekly application of larvicides to all potential breeding habitats observed by community-based staff assigned to defined areas of approximately $0.6 \mathrm{~km}^{2}$ [19-21]. In order to enable effective management of routine larvicide application activities, the adult mosquito surveillance system for this programme needs to report mosquito densities at correspondingly high spatial and temporal resolution. This prompted development and evaluation of a safe, sensitive, cheap, practical and affordable alternative to HLC that allows intensive and extensive monitoring of malaria vectors. A series of Ifakara Tent Trap (ITT) designs have been tried and the $\mathrm{B}$ design has proven efficacious [22] and effective [23] in terms of both number and species composition of mosquitoes caught. It is also cost-effective relative to other sampling methods in terms of cost per mosquito trapped [23]. The B design exposed human subjects to mosquito bites while emptying the large trap chamber [22,23], this model has since been modified to circumvent this problem, but the new design (C) was not available at the time of this study [24]. The ITT appears to be the most promising method for routine surveillance of biting densities of host-seeking mosquitoes in this setting and may be useful in a variety of African settings.

While monitoring host-seeking mosquito densities are an essential part of understanding disease, samples of resting mosquitoes [25] are also required to enable assessment of host feeding patterns through blood meal analysis [26-28]. The proportion of blood meals that each vector species obtains from humans is a critical determinant of, not only transmission intensity, but also the efficacy of interventions targeted at humans or the houses they live in [29-35]. Sample of resting mosquitoes for blood meal analyses are therefore important for selecting appropriate control strategies, particularly as vector population composition may become dominated by zoophagic species once high coverage by insecticidetreated nets [36-38] or indoor residual spraying [39-41] is achieved. ITT and HLC both primarily sample hostseeking mosquitoes [22-24] so either resting collection techniques [42-44] or window exit traps (WET) [44] are required to effectively characterize the feeding behaviours of vector mosquitoes that are relevant to intervention efficacy and selection.

The WET has been found useful for monitoring malaria vector density trends in Southern Africa [45,46], Equatorial Guinea [47] and for vectors of Japanese encephalitis [48] in Korea. However, their sensitivity is likely to be site-specific and strongly influenced by house design. Resting boxes were found to be highly selective in sampling specific mosquito species in coastal areas of the United States of America [49], but have also shown potential for monitoring Culex quinquefasciatus and Aedes aegypti in urban Brazil [50].

This article therefore presents an assessment of a number of mosquito trapping methods compared with HLC catches in Dar es Salaam, including the widely used Centers for Disease Control and Prevention miniature Light Trap (LT) and the WET design commonly used in programmatic contexts, in a rigorous formal comparison for the first time in this urban setting. We also assessed whether catches with the B design of the ITT best represent the indoor or outdoor fractions of mosquito populations because, although this device is placed outdoors, it does resemble a small house and requires the mosquito to enter it so it may selectively sample indoor-biting mosquitoes.

\section{Methods}

\section{Study site}

This study was conducted at Mchikichini and Jangwani wards situated along the edge of Msimbazi River Valley in urban Dar es Salaam, the largest and most economically important city in Tanzania. The city is located at the shores of Indian Ocean coast with humid and hot climatic condition [43]. There are classically two rainy seasons: a main rainy season from March to June and a shorter, less intense rainy season from October to December [1].

Dar es Salaam is also the home of the UMCP, a community-based vector control programme which primarily implements locally-supervised larviciding applied on a weekly basis at the neighbourhood level with vertical oversight from the city council [1,19-21,23,51-56]. An. gambiae sibling species can grow from egg to adult in one week or less [33,57] so the adult mosquito surveillance system for this programme needs to be, not only affordable and practical [23], but also both spatially and temporally intensive to detect coverage gaps as they occur on such fine geographic scales as neighbourhoods, housing clusters and even individual plots $[20,21]$ on a weekly or even daily basis $[19,58]$. The need for sensitive adult malaria mosquito surveillance in this setting is compounded by low levels of local malaria transmission and correspondingly sparse vector populations that mediate it. 
Transmission of malaria in urban Dar es Salaam is generally low with an entomologic inoculation rate of about one or less infectious bite per person per year [19], corresponding to the approximate limit of detection of malaria transmission by most entomological surveillance systems [59]. Members of the Anopheles gambiae complex (An. gambiae sensu stricto, An. arabiensis, An. merus) and An. funestus are the primary malaria vector in this setting, with An. gambiae s.s. and An. arabiensis being most important [1]. While the nightly biting peak of $A n$. gambiae s.s. in Dar es Salaam is consistent with that of classical reports [33], recent observations show that this vector species, together with $A n$. arabiensis, tends to bite predominantly outdoors $[1,60]$.

\section{Trapping methods}

Resting boxes (RB)

Resting boxes made of cardboard with one open end and black cotton cloth lined inside them [23], were each placed indoor in a room occupied by a person and outdoor in a shaded area. Mosquitoes caught were retrieved from the boxes using a hand-held aspirator from 8.00 am to 9.00 am on the morning following each sampling night.

\section{Window exit trap (WET)}

Window exit traps are rectangular boxes made of a wooden frame covered in Teflon ${ }^{\circledR}$-coated woven fiberglass netting, with a slit-shaped rectangular tilted wire opening at one side as a mosquito entrance (Figure 1A) and a sealable cotton sleeve aspirator inlet on the other side. The trap is first attached to a plywood sheet with screws and then the board plus trap combination is screwed to a house window frame (Figure 1B). Note that the edges of the plywood were wrapped with a foam seal to cover the gap between the board and the wall of the house, as well as protecting the wall from being scratched by the board. The traps were installed only to houses without intact screens or houses whose owners provided written informed consent to remove the screen under condition of being compensated with

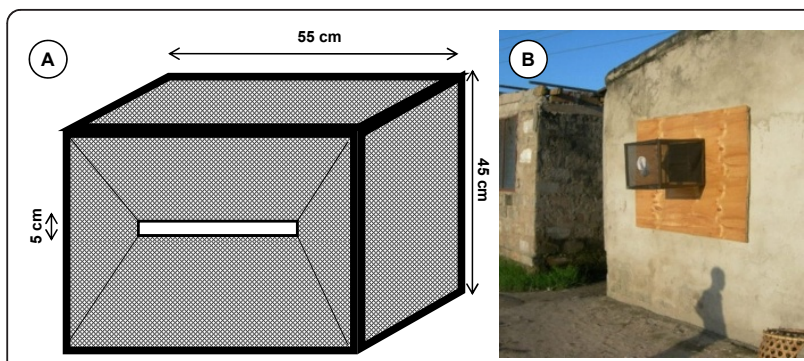

Figure 1 Window exit trap before fixing to a house window (A), and after installation (B) free installation of new screening at the end of the study. Mosquitoes were retrieved from the trap using hand-held aspirator through a sealable sleeve from 8.00 am to 9.00 am.

\section{Centers for Disease Control and Prevention miniature light} traps (LT)

CDC miniature light traps (model 512) with inflorescent bulbs were each hung inside a house near an occupied bed covered with either an untreated net or a long lasting insecticidal net (LLIN), with one block in each location assigned to the two types of nets to test for the effect of net treatment upon LT trap efficiency. The Permanet $2.0^{\mathbb{R}}$ brand of LLIN was used. The trap was hung approximately $150 \mathrm{~cm}$ from the floor surface and placed with the pan touching one side of the net at the end where the occupant's feet lay [61].

Ifakara tent trap (ITT Design B)

The B design of the ITT was placed approximately $5 \mathrm{~m}$ outside the house with a team member sleeping inside it and mosquitoes were collected in the morning as previously described [22,23]. The C design of ITT [24] was not used because it had not been developed and evaluated at the time.

\section{Human landing catch (HLC)}

To conduct HLC, each adult male collector exposed his lower limbs and collected the mosquitoes when they landed on his legs with an aspirator $[1,27,44,62,63]$. HLC was conducted by a single catcher at each station for 45 minutes each hour, allowing 15 minutes break for rest. To obtain full hourly biting densities, the catches for each hour were therefore divided by 0.75 [1]. Collections were conducted both indoors and outdoors in accordance with the experimental design described below.

\section{Experimental design}

Four blocks (two from Mchikichini ward and the remaining two from Jangwani ward) of three houses each, with correspondingly matched outdoor catching stations about $5 \mathrm{~m}$ away from each house were selected. Only houses with open eaves and without ceiling boards, made of blocks with plastered walls and corrugated iron roofs, were chosen and they were distributed approximately 50 m apart. In each location, the two blocks were set up so that one block had all participants protected with untreated nets while those in the other slept under LLINs. As described in the section entitled Ethical clearance and protection of human participants, these were planned based on the existing ownership of nets so that participants only experienced either no change or an increase in protection against mosquitoes and malaria: only participants lacking a net were provided with an untreated net and participants already owning a net of any description were provided with an Perma Net $2.0^{\circledR}$ LLIN (Polyester treated with deltamethrin, developed by 
Vastergaard Frandsen A/S Kolding, Denmark) [64-66]. The resting box, ITT design $\mathrm{B}$, and HLC were placed in the corresponding respective indoor stations so that the combined indoor and outdoor stations at each house within each block could be considered to represent the conventional HLC gold standard, alternative host-seeking catching methods or methods for sampling resting and house-exiting mosquitoes, respectively (Figure 2). These indoor-outdoor combinations were rotated through all three houses of each block (Figure 3 ) for a total of thirteen complete rotations in $3 \times 3$ Latin Square experiment design. This experiment was conducted between $6^{\text {th }}$ May and $2^{\text {rd }}$ July 2008 period, corresponding to the main rainy season and annual peak mosquito biting densities [52]. Mosquitoes were collected from 19.00 to $08.00 \mathrm{~h}$ each night.

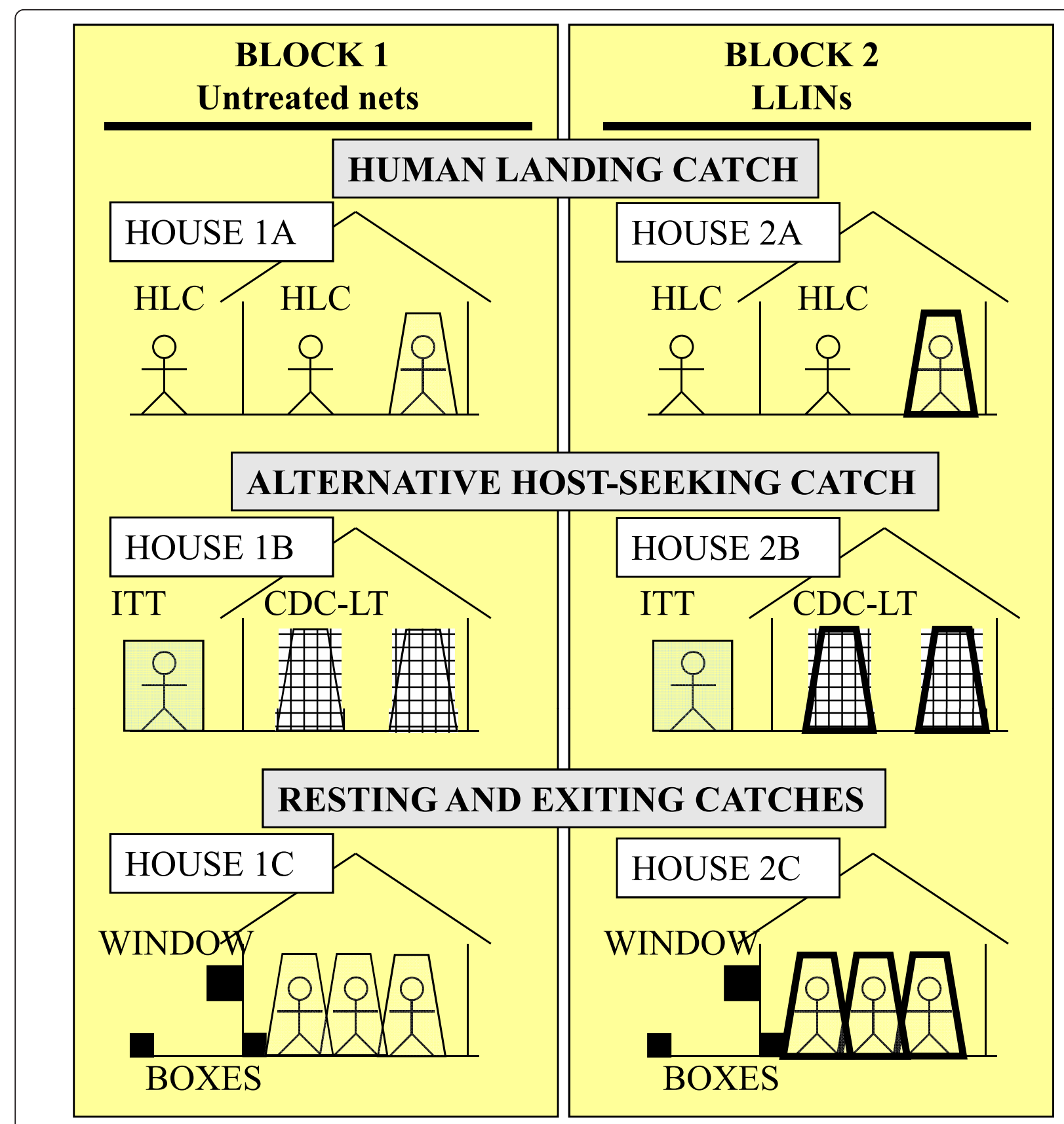

Figure 2 Schematic illustration of a typical night's experimental set up (arrangement 1 as illustrated in figure 3) at one location with two blocks, one of which has occupants using untreated nets while the other has participants using long-lasting insecticidal nets (LLINs). 


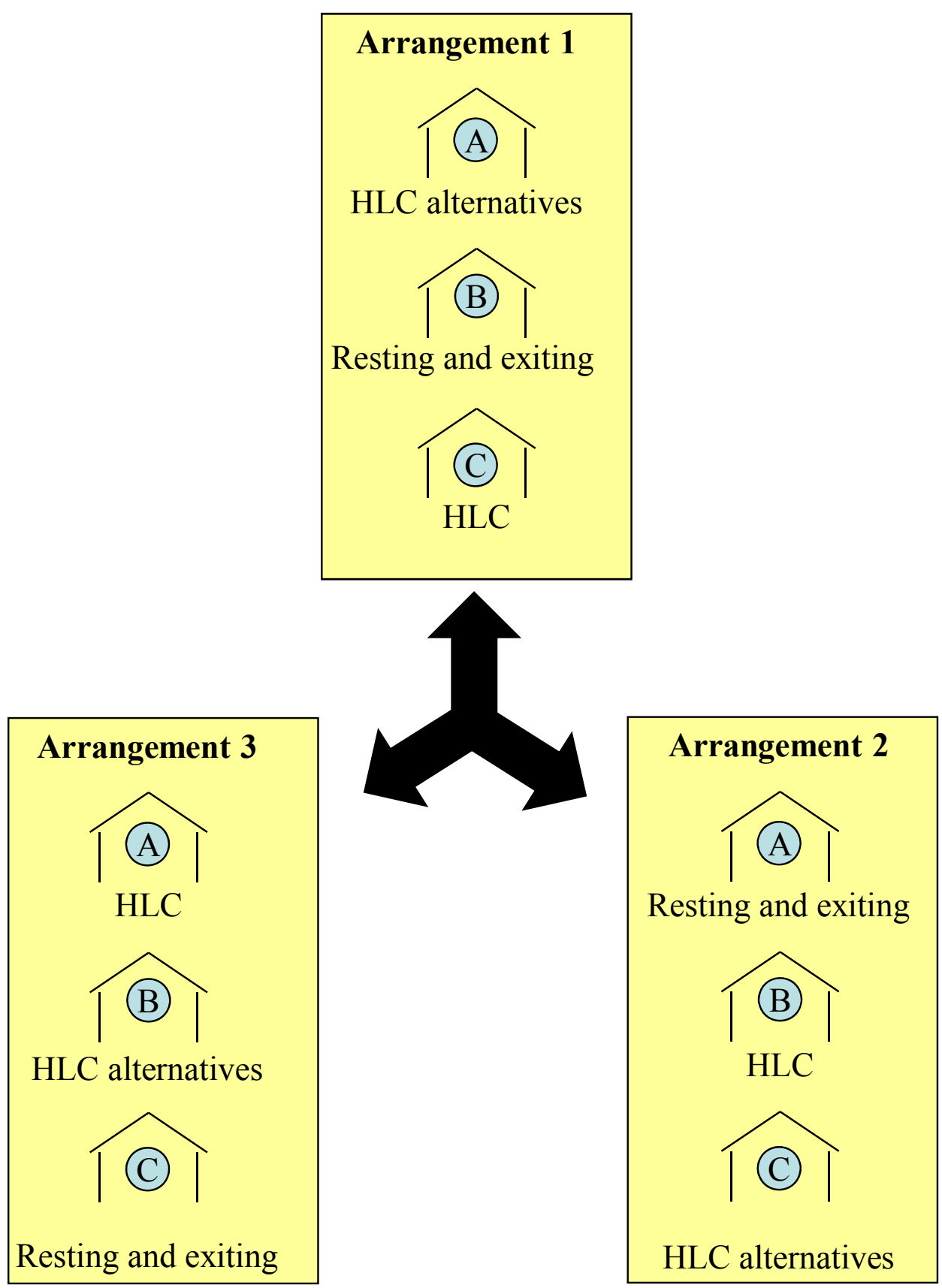

Figure 3 Schematic presentation of three possible arrangements of trapping methods rotated in order through the three houses in any given block. Note that the letters in blue circle represent the identifier within the block for each house, specified as $1 \mathrm{~A}, 1 \mathrm{~B}$ and $1 \mathrm{C}$ for houses in block 1 and $2 \mathrm{~A}, 2 \mathrm{~B}$ and $2 \mathrm{C}$ in for houses in block 2.

\section{Processing of Samples}

All Anopheles mosquitoes caught were sorted and morphologically identified [57] with the aid of a stereomicroscope in the field. A total of 1180 An. gambiae s.l from all traps, were stored in tubes with desiccated silica for subsequent identification to sibling species level by polymerase chain reaction [67]. All Culex were counted, categorized as male or female and discarded.

\section{Data analysis}

\section{Sensitivity differences among trapping methods}

Data analyses were computed using SPSS version 16.0 for Microsoft Windows (SPSS Inc., Chicago IL). Generalized estimating equations (GEE) were employed to assess the influence of trap type upon mosquito catches by treating house as subject variable with trap typeindoor/outdoor assignment combination and date as 
within-subject variables. Catches for female An. gambiae s.l. and Culex spp, were each treated as the dependent variable in separately fitted models. Normal distribution with a natural logarithm link function and exchangeable working correlation matrix were selected for these dependent variables. In the first place for fitting to the catches of $A n$. gambiae s.l., all trap types were included in the model, but yielded inestimable parameter values for both indoor and outdoor resting boxes so these two methods were thereafter removed from the fitted dataset.

\section{The distribution of mosquito taxa among sampling methods and correlation of the catches}

Trap type may affect taxonomic composition of mosquito catches [68] so the influence of trapping method upon the distribution of mosquitoes was analyzed by $\chi^{2}$ test [69]. Comparison of multiple pair-wise Pearson correlation tests using logarithmically transformed data $\left(\log _{10}(x+1)\right.$ for An. gambiae s.l. and $\log _{10}(x)$ for Culex spp of female catches aggregated by date was used to test whether the catches by the ITT best represent the indoor or outdoor biting catches.

\section{The effect of net type on the indoor versus outdoor distribution of mosquitoes}

The only method which yielded sufficient numbers of An. gambiae s.l. and for which both indoor and matching outdoor catches in the same house and night were available was HLC. Comparing the effect of LLINs versus untreated nets upon catches was therefore only possible for this particular method. All mosquitoes caught with HLC in a given house and on a particular night were either caught indoors or outdoors, hence the distributions of $A n$. gambiae s.l. with regards to net type was analyzed by binary logistic regression, treating indoor versus outdoor catches of An. gambiae s.l. as binary outcome.

\section{Ethical clearance and protection of human participant}

Ethical approval was obtained from Institutional review board of Ifakara Health Institute in Tanzania (IHI/IRB/ No. A50) and Medical Research Coordination Committee of the National Institute of Medical Research in Tanzania (NIMR/HQ/R. 8c/Vol. ii/03) and the Ethics Committee of the Liverpool School of Tropical Medicine in the UK (09.60). Written informed consent describing the potential risks and benefits of the study was obtained from all study participants before commencing the study and re-confirmed on each experimental night. Volunteers were screened for malaria parasites by microscopy during recruitment and on a weekly basis throughout the experiment. Those who were found malaria positive were offered treatment free of charge with Artemether-Lumefantrane (Co-Artem ${ }^{\circledR}$, Roche, Basel, Switzerland), the recommended first-line treatment for malaria in the United Republic of Tanzania. The untreated net versus LLIN blocks were assigned so that no individual participant who already had a net was provided with an untreated net to replace it: participants lacking a net were provided either an untreated net or an LLIN while individuals with an existing net, untreated or otherwise, were all provided with a free Perma Net ${ }^{\circledR}$ 2.0 LLIN.

\section{Results}

Sensitivity of alternative traps relative to indoor human landing catch

The number of mosquitoes caught by each collection method is shown in Table 1. The RB, WET, and the LT caught far less An. gambiae s.l. than the indoor HLC reference method. ITT was the only alternative method that caught useful numbers of this vector complex (Table 1), with approximately one quarter the sensitivity of indoor HLC (Table 2). The LT, however, appeared relatively sensitive for sampling Culex spp, exceeding even the number caught by the ITT (Table 1 and 2). All alternative trapping methods, with the exception of the outdoor HLC, sampled significantly less An. gambiae s.l. than the indoor HLC reference method (Table 2). The outdoor HLC, caught as many An. gambiae s.l. and significantly more Culex spp than the indoor HLC reference method (Table 2).

\section{Sibling species composition of An. gambiae sensu lato} Respectively, 96\% (871) and 4\% (41) of 912 (7, 10, 22, 94 and 779 Sub sample from RB, WET, LT and HLC respectively) successfully amplified specimens of $A n$. gambiae s.l. were An. gambiae s.s. and An. arabiensis. This implies that the results presented here overwhelmingly reflect the response of $A n$. gambiae s.s. to these traps.

\section{Effect of sampling technique upon taxonomic composition of female mosquito and correlation of catches}

An. gambiae s.l. (2.78\%), An. funestus (0.05\%), An. ziemanii (1.32\%) and Culex spp (95.85\%) were the only mosquitoes captured in this study. Trap type significantly affected the composition of catches $\left(\chi^{2}=\right.$ 607.408 , degrees of freedom $=18, \mathrm{P}<0.001)$. Apart from such an overall $\chi^{2}$ all pair-wise $\chi^{2}$ comparisons of either outdoor HLC or any of the alternative methods with indoor HLC proved significant $(\mathrm{P} \leq 0.0001)$. As illustrated in Figure 4 the catches of An. gambiae s.l. and Culex spp by ITT correlated consistently slightly better with those of the indoor HLC $\left(\mathrm{r}^{2}=0.619, \mathrm{P}<\right.$ 0.001 and $\mathrm{r}^{2}=0.304, \mathrm{P}=0.001$, respectively) than the outdoor HLC $\left(\mathrm{r}^{2}=0.423, \mathrm{P}<0.001\right.$ and $\mathrm{r}^{2}=0.228, \mathrm{P}=$ 0.001 , respectively). However, this pattern does not hold 
Table 1 Number of mosquitoes caught by different methods and crude estimates of sensitivity relative to indoor human landing catch

\begin{tabular}{|c|c|c|c|c|}
\hline Collection methods & Trap night & Total catch & Mean catch & Relative sensitivity \\
\hline \multicolumn{5}{|l|}{ Anopheles gambiae s.l. } \\
\hline Resting boxes indoor & 156 & 6 & 0.038 & 0.01 \\
\hline Resting boxes out & 156 & 3 & 0.019 & 0.005 \\
\hline Window trap & 156 & 21 & 0.135 & 0.036 \\
\hline CDC light trap & 155 & 30 & 0.194 & 0.052 \\
\hline Ifakara tent trap & 156 & 216 & 1.385 & 0.374 \\
\hline HLC outdoor & 156 & 748 & 4.795 & 1.294 \\
\hline HLC indoor & 156 & 578 & 3.705 & NA \\
\hline \multicolumn{5}{|l|}{ Anopheles funestus } \\
\hline Resting boxes indoor & 156 & 0 & 0 & 0 \\
\hline Resting boxes outdoor & 156 & 0 & 0 & 0 \\
\hline Window trap & 156 & 0 & 0 & 0 \\
\hline CDC light trap & 155 & 0 & 0 & 0 \\
\hline Ifakara tent trap & 156 & 1 & 0.006 & 0.158 \\
\hline HLC outdoor & 156 & 19 & 0.122 & 3.210 \\
\hline HLC indoor & 156 & 6 & 0.038 & NA \\
\hline \multicolumn{5}{|l|}{ Anopheles zeimanii } \\
\hline Resting boxes indoor & 156 & 4 & 0.03 & 0.017 \\
\hline Resting boxes outdoor & 156 & 2 & 0.01 & 0.005 \\
\hline Window traps & 156 & 2 & 0.01 & 0.005 \\
\hline CDC light traps & 155 & 2 & 0.01 & 0.005 \\
\hline Ifakara tent traps & 156 & 9 & 0.06 & 0.033 \\
\hline HLC outdoors & 156 & 460 & 2.95 & 1.629 \\
\hline $\mathrm{HLC}$ indoors & 156 & 283 & 1.81 & NA \\
\hline \multicolumn{5}{|l|}{ Culex spp } \\
\hline Resting boxes indoor & 156 & 293 & 1.878 & 0.017 \\
\hline Resting boxes outdoor & 156 & 931 & 5.968 & 0.053 \\
\hline Window traps & 156 & 2208 & 14.153 & 0.125 \\
\hline CDC light traps & 155 & 7435 & 47.968 & 0.423 \\
\hline Ifakara tent traps & 156 & 6585 & 42.212 & 0.372 \\
\hline HLC outdoors & 156 & 20163 & 129.250 & 1.140 \\
\hline $\mathrm{HLC}$ indoors & 156 & 17688 & 113.385 & NA \\
\hline
\end{tabular}

$\mathrm{NA}=$ not applicable because this is a reference method.

consistently when previous field studies of the same trap design are considered: Correlation results from the previous study in a rural setting for $A n$. gambiae s.l. were $\left(\mathrm{r}^{2}=0.162 \mathrm{P}=0.098\right.$ and $\mathrm{r}^{2}=0.462, \mathrm{P}=0.002$ for ITT versus indoor and outdoor HLC, respectively) and $\left(\mathrm{r}^{2}=\right.$ $0.452, \mathrm{P}=0.002$ and $\mathrm{r}^{2}=0.260, \mathrm{P}=0.033$ for Culex spp by ITT versus indoor and outdoor HLC, respectively.

\section{Effect of long-lasting insecticidal nets upon mosquito sampling}

Human landing catch was the only method for which sufficient numbers of $A n$. gambiae s.l. were caught to assess the impact of LLINs upon the relative fraction of mosquitoes found inside or outside houses. There was no significant difference in the proportion of $A n$. gambiae s.l. caught indoors between LLINs and untreated bed nets houses (Table 3 ).

\section{Discussion}

Sustained control of pathogen- transmitting mosquitoes requires sensitive and representative surveillance. This study compares a wide range of trapping methods, and demonstrates very poor performance of the RB, WET and LT for sampling adult malaria mosquitoes. This implies that such tools are not appropriate for surveillance and monitoring the impact of mosquito control 


\begin{tabular}{|c|c|c|}
\hline Collection methods & $\mathrm{RR}[95 \% \mathrm{Cl}]$ & $P$ value \\
\hline \multicolumn{3}{|l|}{ Anopheles gambiae s.l. } \\
\hline Resting boxes indoor & $\mathrm{NE}$ & NE \\
\hline Resting boxes outdoor & $\mathrm{NE}$ & $\mathrm{NE}$ \\
\hline Window exit trap & $0.01[0.002,0.034]$ & $<0.001$ \\
\hline CDC light trap & $0.02[0.009,0.032]$ & $<0.001$ \\
\hline Ifakara tent trap & $0.26[0.208,0.330]$ & $<0.001$ \\
\hline HLC outdoor & $1.07[0.851,1.356]$ & 0.549 \\
\hline HLC indoor & $1.00^{*}$ & NA \\
\hline \multicolumn{3}{|l|}{ Culex spp } \\
\hline Resting boxes indoor & $0.02[0.010,0.026]$ & $<0.001$ \\
\hline Resting boxes outdoor & $0.07[0.020,0.274]$ & $<0.001$ \\
\hline Window exit trap & $0.11[0.077,0.166]$ & $<0.001$ \\
\hline CDC light trap & $0.50[0.280,0.893]$ & 0.019 \\
\hline Ifakara tent trap & $0.34[0.256,0.461]$ & $<0.001$ \\
\hline HLC outdoor & $1.17[1.077,1.278]$ & $<0.001$ \\
\hline HLC indoor & $1.00^{*}$ & NA \\
\hline
\end{tabular}

$\mathrm{RR}=$ relative rate, $\mathrm{Cl}=$ confidence interval, $\mathrm{NE}=$ not estimable. $\mathrm{NA}=$ not applicable because this is a reference method. * Reference value.

measures in this urban setting where the UMCP targets relatively sparse populations of Anopheles malaria vectors. These results also confirm the previous observational reports that the LT has very low sensitivity in this urban setting [19]. This cannot be explained by the observation that An. gambiae is exophagic in this setting $[1,60]$ because the reference HLC method was also conducted indoors. While no particular explanation is obvious for such surprisingly poor performance by LT, we speculate that the light source from the LT, which is thought to play a vital role in attracting mosquitoes [70], may have competed poorly for the attention of Anopheles in this highly illuminated [71], urbanized environment.

Some reports have suggested that the RB baited with urine odour are useful [72] for surveillance of $A n$. arabiensis, the most exophilic [73] sibling species of the $A n$. gambiae s.l. complex $[57,74]$ in lower Moshi, Tanzania. However, this conclusion was neither supported by this study nor by a previous effectiveness evaluation in Dar es Salaam [23] which relied on unbaited RB. While these results are discouraging, it may be possible to improve the sensitivity of the approach by lining the boxes internally either with a sticky surface [75] or a collapsible collection bag to maximize the catch size, because we observed that mosquitoes which entered the $\mathrm{RB}$ often escaped, particularly during retrieval.

Likewise the weak performance by WET can be possibly partly explained by the architectural of the local houses. Most houses used in this study apart from having open eaves and lacking a ceiling, also had walls separating adjacent rooms which did not reach the roof. It was therefore likely that many mosquitoes which entered a room fixed with WET exited via other rooms without a WET. Nevertheless, without such ready exits, there is also limited opportunity for mosquitoes to enter houses in the first place so there may be a fundamental a limit to how efficacious such exit traps can be outside of experimental huts. Furthermore, variations in housing design are a normal feature of representative mosquito sampling so these disappointing results should be interpreted at face value until proven otherwise. It should also be noted that while this approach has been applied and advocated in a number of programmatic settings $[45-47,76]$, to our knowledge this is the first time the efficacy of this trapping method has been formally evaluated in comparison with HLC or other standard methods in typical residences rather than in experimental huts.

The correlation results obtained from this study indicated the catches from ITT relate better to those from the indoor rather than outdoor HLC but the taxonomic composition of female mosquitoes caught by ITT does not match those of the indoor HLC and re-analysis of data obtained from the previous study in rural setting [22], yield contradictory correlation results that although consistent with this study for Culex spp the reverse was observed for the An. gambiae s.l. population, consisting primarily of $A n$. arabiensis, in that study. It therefore remains unclear whether densities measured by ITT best reflect indoor or outdoor catches.

Consistent with our previous study of ITT evaluation $[22,23]$ it appears that this trap has potential for both research and routine programmatic surveillance applications.

Although, pyrethroid treated bed nets are commonly thought to reduce house entry by $A n$. gambiae s.l. [77-80], the particular LLIN product evaluated in this study failed to significantly deter An. gambiae s.l. from entering local houses. This observation is consistent with experimental hut studies in other parts of Tanzania $[64,65]$ and Benin [81]. We conclude that, in this urban Tanzanian setting, negligible protection against malaria transmission exposure can be expected for non-users sharing the same house. This observation implies also that the reliability of human landing catches in estimating indoor An. gambiae s.l. catches in this setting is not affected by the presence of this particular brand of LLINs.

\section{Acknowledgements}

We would like to appreciate the residents of Jangwani and Mchikichini, Dar es Salaam for their cooperation throughout the study. Special thanks go to 


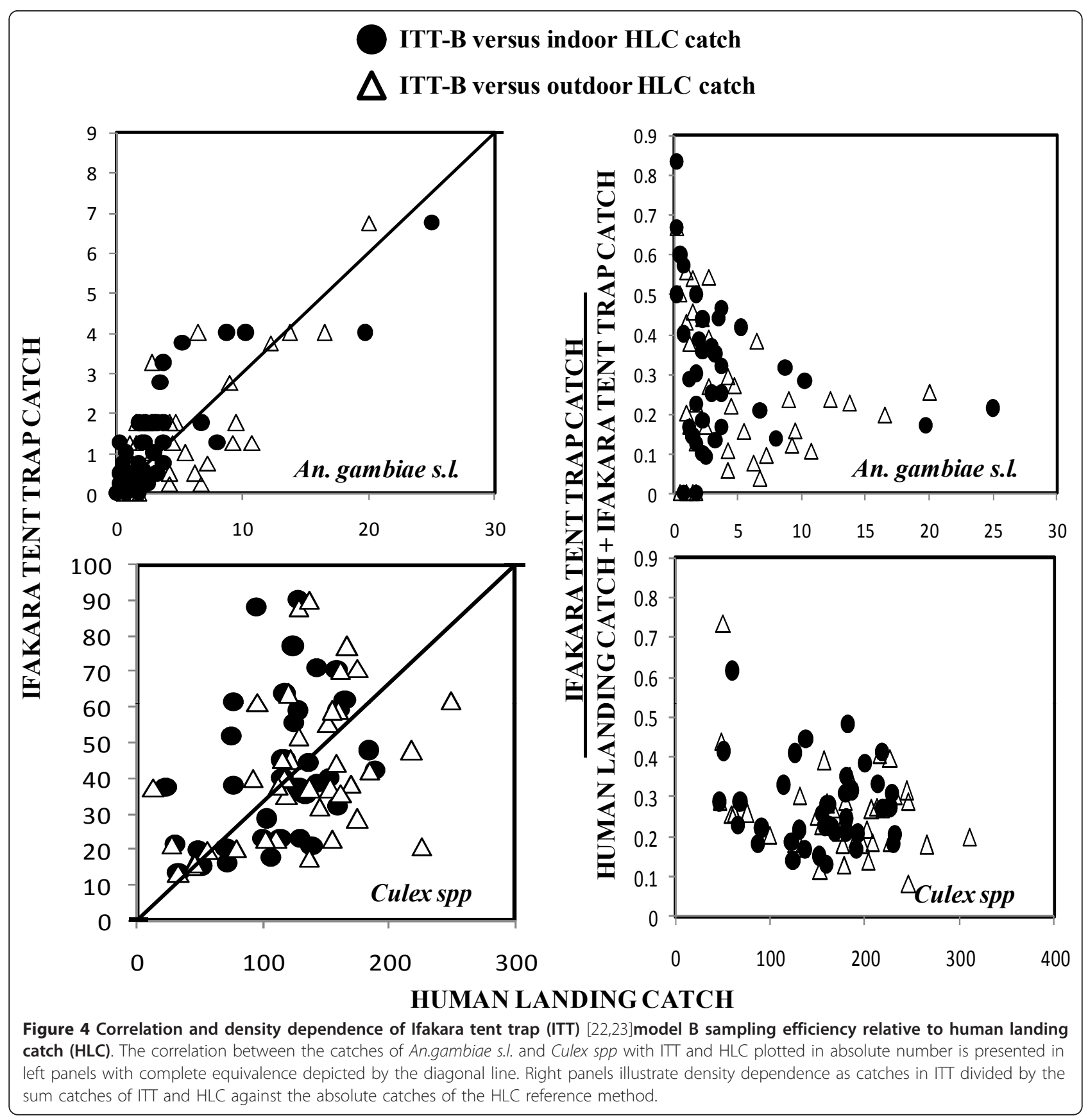

Table 3 The effect of treatment on proportion of An. gambiae s.l. sampled indoor and outdoor determined by logistic regression as described in the method sections

\begin{tabular}{llll}
\hline Categorical variables & An. gambiae s.l. caught indoor (\%) & OR[95\%Cl] & $P$ \\
\hline Treatment & & & \\
\cline { 1 - 1 } Long lasting net & $44.94(333 / 741)$ & $1.13[0.91,1.41]$ & 0.265 \\
Untreated bed net & $41.88(245 / 340)$ & $1.00^{*}$ & NA \\
\hline
\end{tabular}

$\mathrm{NA}=$ not applicable because this is a reference group.

$\mathrm{OR}=$ odds ratio, $\mathrm{Cl}=$ Confidence interval, $1.00 *$ reference value. 
all the mosquito catchers for their commitment to this work. We also thank Doctors Hilary Ranson and Louise Kelly-Hope for their constructive comments on this manuscript. Financial support was provided by the Ifakara Health Institute (Core Funding), the Wellcome Trust (Research Career Development Fellowship number 076806 awarded to GFK) and the Bill \& Melinda Gates Foundation through the Malaria Transmission Consortium (Award number 45114), coordinated by Dr. Neil Lobo and Professor Frank Collins at Notre Dame University.

\section{Author details}

'Ifakara Health Institute, Coordination Office, PO Box 78373, Kiko Avenue, Mikocheni, Dar es Salaam, United Republic of Tanzania. '2Liverpool School of Tropical Medicine, Pembroke place, Liverpool L3 5QA, UK. 3Salvation Army of Tanzania, Monitoring and Evaluation Department, P.O. Box 1273, Kilimanjaro, United Republic of Tanzania.

\section{Authors' contributions}

NJG designed and implemented mosquito sampling protocol in collaboration with other authors. He supervised the data collection, performed analysis, interpreted the results and drafted the manuscript in consultation with other authors. PPC, JP supported the design and implementation of the study. GFK supervised the design, implementation of the study, data analysis and drafting of the manuscript. All authors read and approved the final manuscript.

\section{Competing interests}

The authors declare that they have no competing interests.

Received: 29 November 2010 Accepted: 21 March 2011 Published: 21 March 2011

\section{References}

1. Geissbühler $Y$, Chaki $P$, Emidi B, Govella NJ, Shirima R, Mayagaya $V$, Mtasiwa D, Mshinda H, Fillinger U, Lindsay SW, Kannady K, Caldas de Castro M, Tanner M, Killeen GF: Interdependence of domestic malaria prevention measures and mosquito-human interactions in urban Dar es Salaam, Tanzania. Malar J 2007, 6:126.

2. Waynd S, Melrose WD, Durrheim DN, Carron J, Gyspong M: Understanding the community impact of lymphatic filariasis: a review of the sociocultural literature. Bull World Health Org 2007, 85:421-500.

3. Pedersen EM, Kiama WL, Swai ABM, Kihamia CM, Rwiza H, Kisumku UM: Bancroftian filariasis on Pemba Island, Zanzibar, Tanzania: An update on status in urban and semi-urban communities. Trop Med Int Health 1999 4:295-301

4. Maxwell CA, Curtis CF, Haji H, Kisumku S, Thalib Al, Yahya SA: Control of Bancroftian filariasis by integrating therapy with vector control using polystyrene beads in wet pit latrine. Trans R Soc Trop Med Hyg 1990, 84:709-714.

5. Bockarie MJ, Pedersen EM, White GB, Michael E: Role of vector control in the global program to eradicate lymphatic filariasis. Ann Rev Entomol 2009, 54:469-487.

6. Hotez PJ, Kamath A: Neglected tropical diseases in sub-Saharan Africa: review of their prevalence, distribution and disease burden. PLoS Negl Trop Dis 2009, 3:e412.

7. Curtis CF, Feachem RG: Sanitation and Culex pipiens mosquitoes: a brief review. J Trop Med Hyg 1981, 84:17-25.

8. Smith $\lrcorner$, Fonseca DM: Rapid assay for identification of members of the Culex (Culex) pipiens complex, their hybrids and other sibling species (Diptera: Culicidae). Am J Trop Med Hyg 2004, 70:339-345.

9. Cantey PT, Rout J, Rao G, Williamson J, Fox LM: Increasing compliance with mass drug administration program for Lymphatic Filariasis in India through education and lymphedema management programs. PLoS Negl Trop Dis 2010, 4:e728.

10. Raghavan NGS: Epidemiology of filariasis in India. Bull World Health Org 1957, 16:553-579.

11. Nathan MB: Bancroftian filariasis in coastal North Trinidad, West Indies: intensity of transmission by Culex quinquefasciatus. Trans $R$ Soc Trop Med Hyg 1981, 75:721-730.

12. Janousek TE, Lowrie RC: Vector competency of Culex quinquefasciatus (Haitian strain) following infection with Wuchereria bancrofti. Trans $R$ SOC Trop Med Hyg 1989, 83:679-680.
13. Zhang S, Cheng F, Webber R: A successful control program for lymphatic filariasis in Hubei, China. Trans R Soc Trop Med Hyg 1994, 88:510-512.

14. Service $M$, (ed): Medical entomology for students. Cambridge University Press, Third 2004, 285.

15. Malecela MN, Mwingira U, Mwakitalu ME, Kabali C, Michael E, MacKenzie CD: The sharp end- experiences from the Tanzanian programme for the elimination of lymphatic filariasis: notes from the end of the road. Ann Trop Med Parasitol 2009, 103:53-57.

16. Malecela MN, Lazarus W, Mwingira U, Mwakitalu E, Makene C, Kabali C, Mackenzie C: Eliminating LF: A progress report from Tanzania. $J$ Lymphoedema 2009, 4:10-12.

17. MacKenzie CD, Lazarus WM, Mwakitalu ME, Mwingira U, Malecela MN: Lymphatic filariasis: patients and global elimination programme. Ann Trop Med Parasitol 2009, 103:41-51.

18. Simonsen PE, Pedersen EM, Rwegoshora RT, Malecela MN, Derua YA, Magesa SM: Lymphatic filariasis control in Tanzania: effect of repeated mass drug administration with Ivermectin and Albendazole on infection and transmission. PLoS Negl Trop Dis 2010, 4:e696.

19. Fillinger U, Kannady K, William G, Vanek MJ, Dongus S, Nyika D, Geissbuhler Y, Chaki PP, Govella NJ, Mathenge EM, Singer BH, Mshinda H, Lindsay SW, Tanner M, Mtasiwa D, Castro MC, Killeen GF: A tool box for operational mosquito larval control; preliminary results and early lessons from the Urban Malaria Control Programme in Dar es Salaam. Malar J 2008, 7:20

20. Chaki PP, Govella NJ, Shoo B, Hemed A, Tanner M, Fillinger U, Killeen GF: Achieving high coverage of larval-stage mosquito surveillance: challenges for a community-based mosquito control programme in urban Dar es Salaam, Tanzania. Malar J 2009, 8:311.

21. Dongus S, Nyika D, Kannady K, Mtasiwa D, Mshinda H, Fillinger U, Drescher AW, Tanner M, Castro MC, Killeen GF: Participatory mapping of target areas to enable operational larval source management to suppress malaria vector mosquitoes in Dar es Salaam, Tanzania. Int $J$ Health Geogr 2007, 6(1):37.

22. Govella NJ, Chaki PP, Geissbühler Y, Kannady K, Okumu FO, Charlwood JD, Anderson RA, Killeen GF: A new tent trap for sampling exophagic and endophagic members of the Anopheles gambiae complex. Malar J 2009, $8: 157$

23. Sikulu M, Govella NJ, Ogoma SB, Mpangile J, Kambi SH, Kannady K, Chaki PP, Mukabana WR, Killeen GF: Comparative evaluation of the Ifakara tent trap-B, standardized resting boxes and human landing catch for sampling malaria vectors and other mosquitoes in urban Dar es Salaam, Tanzania. Malar J 2009, 8:197.

24. Govella NJ, Moore J, Killeen GF: An exposure free tool for monitoring adult malaria mosquito populations. Am J Trop Med Hyg 2010, 83(3):596-600.

25. Pates H, Curtis C: Mosquito behavior and vector control. Ann Rev Entomol 2005, 50:53-70

26. Lefevre T, Gouagna LC, Dabire KR, Elguero E, Fontenille D, Renaud F, Costantini C, Thomas F: Beyond nature and nurture: phenotypic plasticity in blood-feeding behavior of Anopheles gambiae s.s. when humans are not readily accessible. Am J Trop Med Hyg 2009, 81(6):1023.

27. Service MW: A critical review of procedures for sampling populations of adult mosquitoes. Bull Entomol Res 1977, 67:343-382.

28. Lyimo IN, Ferguson HM: Ecological and evolutionary determinants of host species choice in mosquito vectors. Trends Parasitol 2009, 25(4):189-196.

29. Killeen GF, Smith TA: Exploring the contributions of bed nets, cattle, insecticides and excitorepellency to malaria control: a deterministic model of mosquito host-seeking behaviour and mortality. Trans $R$ Soc Trop Med Hyg 2007, 101(9):867-880.

30. Killeen GF, Smith TA, Ferguson HM, Mshinda H, Abdulla S, Lengeler C, Kachur SP: Preventing childhood malaria in Africa by protecting adults from mosquitoes with insecticide-treated nets. PLoS Med 2007, 4:e229.

31. Garrett-Jones C: The human blood index of malarial vectors in relationship to epidemiological assessment. Bull World Health Org 1964, 30:241-261.

32. Garrett-Jones C: Prognosis for interruption of malaria transmission through assessment of the mosquito's vectorial capacity. Nature 1964, 204:1173-1175.

33. Gillies MT, DeMeillon B: The Anophelinae of Africa south of the Sahara (Ethiopian zoogeographical region). Johannesburg: South African Institute for Medical Research; 1968 
34. MacDonald G: The epidemiology and control of malaria. London: Oxford University Press; 1957.

35. Bruce-Chwatt $L$, (ed): Diagnostic methods in malaria. London: William Heinemann Medical Books Ltd; 1985.

36. Bayoh MN, Mathias DK, Odiere MR, Mutuku FM, Kamau L, Gimnig JE, Vulule JM, Hawley WA, Hamel MJ, Walker ED: Anopheles gambiae: historical population decline associated with reginal distribution of insecticide-treated bed nets in Western Nyanza Province, Kenya. Malar J 2010, 9:62.

37. Russell TL, Lwetoijera DW, Maliti D, Chipwaza B, kihonda J, Charlwood JD, Smith TA, Lengeler C, Mwanyangala MA, Nathan R, Knols BGJ, Takken W, Killeen GF: Impact of promoting longer-lasting insecticide treatment of bed nets upon malaria transmission in a rural Tanzanian setting with pre-existing high coverage of untreated nets. Malar J 2010, 9:187.

38. Lindblade KA, Gimnig JE, Kamau L, Hawley WA, Odhiambo F, Olang G, Terkuile FO, Vulule JM, Slutsker L: Impact of sustained use of insecticidetreated bednets on malaria vector species distribution and Culicine mosquitoes. J Med Entomol 2006, 42:428-432.

39. Gillies MT, Smith A: Effect of a residual house spraying campaign on species balance in Anopheles funestus group: The replacement of Anopheles funestus Giles with Anopheles rivulorum Leeson. Bull Entomol Res 1960, 51:248-252

40. Gillies MT: A new species of the Anopheles funestus complex (Diptera: Culicidae) from East Africa. Proc Roy Ent Soc London (B) 1962, 31:81-86.

41. Gillies MT, Furlong M: An investigation into behaviour of Anopheles parensis Gillies at Malindi on coast of Kenya. Bull Entomol Res 1964, 55:1-16

42. Kulkarni MA, Kweka E, Nyale E, Lyatuu E, Mosha FW, Chandramohan D, Rau ME, Drakeley C: Entomological evaluation of malaria vectors at different altitudes in Hai district, northeastern Tanzania. J Med Entomol 2006, 43:580-588.

43. Anonymous: The 2002 population and housing census general report. Dar es Salaam, Tanzania: National Bureau of Statistics; 2003.

44. Anonymous: Manual on practical entomology. Part 2. Methods and techniques. Geneva: World Health Organization No.13; 1975.

45. Mouatcho JC, Hargreaves K, Koekemoer LL, Brooke BD, Oliver SV, Hunt MC Indoor collections of Anopheles funestus group (Diptera:Culicidae) in sprayed houses in northern KwaZulu-Natal, South Africa. Malar J 2007, 6:30.

46. Hargreaves K, Hunt RH, Brooke BD, Mthembu J, Weeto MM, Awolola TS, Coetzee M: Anopheles arabiensis and Anopheles quadriannulatus resistance to DDT in South Africa. Med Vet Entomol 2003, 17:417-422

47. Sharp BL, Ridl FC, Govender D, Kuklinski J, Kleinschmidt I: Malaria vector control by indoor residual insecticide spraying on the tropical island of Bioko, Equatorial Guinea. Malar J 2007, 6:52.

48. Chen YK, Chow CY: Methods of sampling populations of the Japanese encephalitis vector mosquitoes in Korea (A preliminary report). Korean J Parasitol 1969, 7:25-28

49. Crans WJ: Resting boxes as mosquito surveillance tools. Proceeding of the eighty-second annual meeting of the New Jersey mosquito control association: 1989 New Jersey mosquito biology and control. Center for vector biology; 1989, 53-57.

50. Barata EAM, Neto FC, Dibo MR, Macoris MLG, barbosa AA, Natal D, Barata JMS, Andriguetti MTM: Capture of culicids in urban areas: evaluation of the resting box method. Rev Saude Publica 2007, 41:1-7.

51. Mukabana WR, Kannady K, Kiama GM, ljumba JN, Mathenge EM, Kiche I, Nkwengulila G, Mboera L, Mtasiwa D, Yamagata Y, van Schayk I, Knols BG, Lindsay SW, Caldas de Castro M, Mshinda H, Tanner M, Fillinger U, Killeen GF: Ecologists can enable communities to implement malaria vector control in Africa. Malar J 2006, 5:9.

52. Geissbühler Y, Kannady K, Chaki PP, Emidi B, Govella NJ, Mayagaya V, Kiama M, Mtasiwa D, Mshinda H, Lindsay SW, Tanner M, Fillinger U, Castro MC, Killeen GF: Microbial larvicide application by a large-scale, community-based program reduces malaria infection prevalence in Urban Dar Es Salaam, Tanzania. PLoS One 2009, 4:e5107.

53. Sattler MA, Mtasiwa D, Kiama M, Premji Z, Tanner M, Killeen GF, Lengeler C: Habitat characterization and spatial distribution of Anopheles sp. mosquito larvae in Dar es Salaam (Tanzania) during an extended dry period. Malar J 2005, 4:4

54. Dongus S, Nyika D, kannady K, Mtasiwa D, Mshinda H, Gosoniu L, Drescher AW, Fillinger U, Tanner M, Killeen GF, Castro MC: Urban agriculture and Anopheles habitats in Dar es Salaam, Tanzania. Geospatial Health 2009, 3:189-210.

55. Wang SJ, Lengeler C, Smith TA, Vounatsou P, Cisse G, Tanner M: Rapid urban malaria appraisal (RUMA) III: Epidemiology of urban malaria in the municipality of Yopougon (Abidjan). Malar J 2006, 5:28.

56. Castro MC, Tsuruta A, Kanamori S, Kannady K, Mkude S: Community-based environmental management for malaria control: evidence from a smallscale intervention in Dar es Salaam, Tanzania. Malar J 2009, 8:57.

57. Gillies MT, Coetzee M: A supplement to the Anophelinae of Africa South of the Sahara (Afrotropical region). Johannesburg: South African Medical Research Institute; 1987.

58. Killeen GF, Tanner M, Mukabana WR, Kalongolela MS, Kannady K, Lindsay SW, Fillinger U, Castro MC: Habitat targeting for controlling aquatic stages of malaria vectors in Africa. Am J Trop Med Hyg 2006, 74:517-518.

59. Beier JC, Killeen GF, Githure J: Entomologic inoculation rates and Plasmodium falciparum malaria prevalence in Africa. Am J Trop Med Hyg 1999, 61:109-113.

60. Govella NJ, Okumu FO, Killeen GF: Insecticide-treated nets can reduce malaria transmission by mosquitoes which feed outdoors. Am J Trop Med Hyg 2010, 82:415-419.

61. Mboera LEG, Kihonda J, Braks MA, knols BGJ, Braks MA, Knols BG: Influence of Centers for Disease Control light trap position, relative to a humanbaited bed net, on catches of Anopheles gambiae and Culex quinquefasciatus in Tanzania. Am J Trop Med Hyg 1998, 59:595-596.

62. Mboera LEG: Sampling techniques for adult Afrotropical malaria vectors and their reliability in the estimation of entomological inoculation rates. Tanzania Health Res Bull 2005, 7:117-124.

63. Anonymous: Malaria entomology and vector control. Learner's Guide. Geneva: World Health Organisation, Trial 2002.

64. Graham K, Kayedi MH, Maxwell C, Kaur H, Rehman H, Malima R, Curtis CF, Lines JD, Rowland MW: Multicountry field trials comparing washresistance of PermaNet and conventional insecticide-treated nets against anopheline and culicine mosquitoes. Med Vet Entomol 2005, 19:72-83.

65. Tungu P, Magesa SM, Maxwell CA, Malima R, Masue D, Sudi W, Myamba J, Pigeon O, Rowland M: Evaluation of PermeNet 3.0 a deltermethrin-PBO combination net against Anopheles gambiae and pyrethroid resistant Culex quinquefasciatus mosquitoes: an experimental hut trial in Tanzania. Malar J 2010, 9:21.

66. Fettene M, Balkew M, Gimblet C: Utilization, retention and bio-efficacy studies of PermaNet in selected villages in Buie and Fentalie districts of Ethiopia. Malar J 2009, 8:114.

67. Scott JA, Brogdon WG, Collins FH: Identification of single specimens of Anopheles gambiae complex by polymerase chain reaction. Am J Trop Med Hyg 1993, 49:520-529.

68. Okumu FO, Madumla EP, John AN, Lwetoijera DW, Sumaye RD: Attracting, trapping and killing disease-transmitting mosquitoes using odor-baited stations-The Ifakara Odor-Baited Stations. Parasit \&Vectors 2010, 3:12.

69. Kirkwood BR: Essentials of medical statistics. Oxford: Blackwell scientific publication; 1988.

70. Costantini C, Sagnon NF, Sanogo E, Merzagora L, Colluzi M: Relationship to human biting collections and influence of light and bednets in CDC light-trap catches of West African malaria vectors. Bull Entomol Res 1998 88:503-511.

71. Miller TA, Stryker R, Wilkinson RN, Esah S: Influence of moonlight and other environmental factors on the abundance of certain mosquito species in light-trap collections in Thailand. J Med Entomol 1970, 17:555-561.

72. Kweka EJ, Mwang'onde BJ, Kimaro E, Msangi S, Massenga CP, Mahande AM: A resting box for outdoor sampling of adult Anopheles arabiensis in rice irrigation schemes of lower Moshi, northern Tanzania. Malar J 2009, 8:82.

73. White GB: Anopheles gambiae complex and disease transmission in Africa. Trans R Soc Trop Med Hyg 1974, 68:279-301.

74. Coetzee M, Craig M, le Sueur D: Distribution of African malaria mosquitoes belonging to the Anopheles gambiae complex. Parasitol Today 2000, 16:74-77.

75. Facchinelli L, Koenraadt CJM, Fanello C, Kijchalao U, Valerio L, Jones JW, Scott TW, Torre A: Evaluation of a sticky trap for collecting Aedes (stegomyia) adults in a dengue-endemic area in Thailand. Am J Trop Med Hyg 2008, 78:904-909. 
76. Ridl FC, Bass C, Torrez M, Govender D, Ramdeen V, Yellot L, Edu AE, Schwabe C, Mohloai P, Maharaj R, Kleinschmeidt I: A pre-intervention study of malaria vector abundance in Rio Muni, Equatorial Guinea: their role in malaria transmission and the incidence of insecticide resistance alleles. Malar J 2008, 7:194.

77. Miller JE, Lindsay SW, Armstrong JRM: Experimental hut trials of bednet impregnated with synthetic pyrethroid and organophosphate insecticides for mosquito control in The Gambia. Med Vet Entomol 1991, 5:465-476

78. Lindsay SW, Adiamah JH, Miller JE, Armstrong JRM: Pyrethroid-treated bednet effects on mosquitoes of the Anopheles gambiae complex. Med Vet Entomol 1991, 5:477-483.

79. Lindsay SW, Adiamah $\mathrm{JH}$, Armstrong JRM: The effect of permethrinimpregnated bed nets on house entry by mosquitoes in The Gambia. Bull Entomol Res 1992, 82:49-55.

80. N'Guessan R, Asidi A, Boko P, Odjo A, Akogbeto M, Pigeon O, Rowland M: An experimental hut evaluation of Permanet $3.0^{\circ}$, a deltamethrinpiperonyl butoxide combination net, against pyrethroid-resistant Anopheles gambiae and Culex quinquefasciatus mosquitoes in southern Benin. Trans R Soc Trop Med Hyg 2010, 104:758-765.

81. Corbel V, Chabi J, Dabire RD, Etang J, Nwane P, Pigeon O, Akogbeto M, Hougard J-M: Field efficacy of a new mosaic long-lasting mosquito net (PermaNet 3.0) against pyrethroid-resistant malaria vectors: A mult centre study in Western and Central Africa. Malar J 2010, 9:113.

doi:10.1186/1756-3305-4-40

Cite this article as: Govella et al: Monitoring mosquitoes in urban Dar es Salaam: Evaluation of resting boxes, window exit traps, CDC light traps, Ifakara tent traps and human landing catches. Parasites \& Vectors 2011 4:40.

\section{Submit your next manuscript to BioMed Central and take full advantage of:}

- Convenient online submission

- Thorough peer review

- No space constraints or color figure charges

- Immediate publication on acceptance

- Inclusion in PubMed, CAS, Scopus and Google Scholar

- Research which is freely available for redistribution

Submit your manuscript at www.biomedcentral.com/submit 